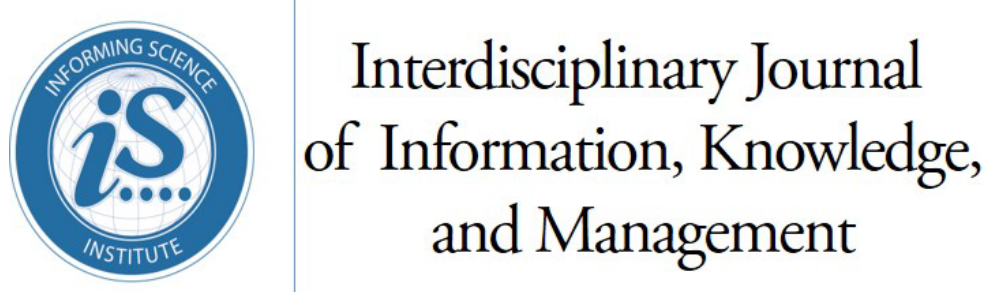

An Official Publication

of the Informing Science Institute

InformingScience.org

IJIKM.org

\title{
Volume 14, 2019 \\ KNOWLEDge SHARING PROCESS AND INNOVATION SUCCESS: EVIDENCE FROM PUBLIC ORGANISATIONS IN SOUTHERN NIGERIA
}

$\begin{array}{lll}\text { Uzoma Heman Ononye* } & \begin{array}{l}\text { University of Nigeria, Enugu } \\ \text { Campus, Enugu, Nigeria }\end{array} & \text { Ononye.uz@gmail.com } \\ \text { Rev. Fr. Anthony Igwe } & \begin{array}{l}\text { University of Nigeria, Enugu } \\ \text { Campus, Enugu, Nigeria, }\end{array} & \text { Anthonyigwe121@gmail.com } \\ \text { * Corresponding author } & & \end{array}$

ABSTRACT

Aim/Purpose

This study investigates the relationship between knowledge sharing process and innovation success with specific emphasis on tacit knowledge. Based on the literature review, we hypothesised that knowledge donating and collecting have a positive relationship with innovation success.

Methodology

The hypotheses were empirically tested using the partial least square path modelling with data collected from twelve state-owned public organisations operating in Southern Nigeria.

Contribution

The research made distinct empirical contributions to the burgeoning literature on knowledge sharing and innovation from the public sector and developing country context.

Findings

Knowledge donating and collecting contribute to innovation success positively and significantly. Knowledge donating effect on innovation success was found to be more significantly positive than the effect of knowledge collecting on innovation success.

Recommendations Public organisations should promote a supportive culture to spur innovation for Practitioners through the frequent share of experiences, information and skills among the various knowledge actors. Public managers should convey the importance of knowledge sharing and its value to knowledge users in clear terms and attend to creating conditions or contexts that encourage people to share knowledge freely and willingly with others. It is apt to improve organisational commitment and support for knowledge sharing activities such as mentorship programs, workshops, conferences, seminars and other related training and de-

Accepting Editor Nelson K. Y. Leung | Received: February 10, 2019| Revised: April 10, 2019 | Accepted: May 19, 2019.

Cite as: Ononye, U. H., \& Igwe, A. (2019). Knowledge sharing process and innovation success: evidence from public organisations in Southern Nigeria. Interdisciplinary Journal of Information, Knowledge, and Management, 14, 183198. https://doi.org/10.28945/4358

(CC BY-NC 4.0) This article is licensed to you under a Creative Commons Attribution-NonCommercial 4.0 International License. When you copy and redistribute this paper in full or in part, you need to provide proper attribution to it to ensure that others can later locate this work (and to ensure that others do not accuse you of plagiarism). You may (and we encourage you to) adapt, remix, transform, and build upon the material for any non-commercial purposes. This license does not permit you to use this material for commercial purposes. 
velopment programs in order to provide opportunities for employees to develop innovation competencies from the transfer of tacit knowledge developed over time from experience. To optimise innovation outcomes from knowledge sharing practices, knowledge sharing should be in tandem with the industry or global best practices.

Future Research Future studies should add interviews to provide depth in terms of insights and substance to the questionnaire, and may extend to public organisation with different ownership structure.

Keywords tacit knowledge, knowledge sharing, knowledge donating, knowledge collecting, innovation success

\section{INTRODUCTION}

The fierce global competition, rapid environmental changes and higher demands for quality services have prompted public organisations to look for competitive advantage for survival (Yeşil Koska \& Buyukbese, 2013). In order to progressively manage the new challenge, knowledge sharing and innovation are increasingly emphasised, as it affects the way organisations perform in an era of constant change (Xiang, Yong, \& Guo, 2009). Trigo (2014) observes that studies on innovation recognise the value of knowledge sharing as a facilitating factor for promoting innovation in organisations. In fact, Reid (2003, cited in Lin, 2007) argues that knowledge sharing creates opportunities for enhancing organisational abilities to generate innovative solutions and efficiencies that provide a competitive advantage (see Abdallah, Khalil, \& Divine, 2012). By interacting and sharing valuable knowledge with others, the individual enhances the capacity to define a problem or situation, and apply this knowledge to act and specifically solve the problem. Hence, an organisational context, which increases knowledge creation and innovation, is a context which favours the exchange of creative ideas and experiences among people (Sáenz, Aramburu, \& Blanco, 2012). It can be said that any attempt to improve organisational innovation need to include practices that leads to the dissemination of innovation ideas with significant performance implications (Vathsala, 2015).

McNabb (2007) argues that, counter to the common perception and belief that innovation is exclusive for the private sector, public organisations do innovate to address emerging issues and new realities and have done so for a long time, especially in an era where uncertainty has ensued. The public sector by its size and complexity remains one of the largest depositories of knowledge, which typically resides as explicit or tacit knowledge (Al-Baporikar, 2014). Explicit knowledge consists of knowledge expressed in words or numbers, codified in paper and electronic formats, and readily shared without the need for discussion. In contrast, tacit knowledge emerges from competencies that are dynamically translated into individual actions and experiences (Santos \& Lopes, 2014). Tacit knowledge is highly personal, subjective and somewhat difficult to communicate in explicit form (Ondari-Okenwa \& Smith, 2009). However, explicit knowledge is not considered enough to be the sustained basis of innovation because its changeability depends on the dynamism of tacit knowledge. If the currency of the knowledge economy is information, the human mind is the bank where it is deposited, invested and exchanged (Omotayo, 2015). The knowledge embedded in the brain of individuals is the seed from which new concepts or ideas sprout, and are therefore central ingredients of the innovation process. Whether through introspection or interaction, the spark of an idea has to come from the mind of an individual or group. This means the share of the tacit component of an organisation's knowledge base has the potential to give public organisations an even more innovative character that would be of strategic importance (Edge, 2005).

Kremp and Mairesse (2003) contend that public organisations are more aware of the fact that competencies for stimulating innovations in the workplace often rely on individuals or on tacit knowledge special to them. However, they are worried about the loss of skilled manpower with first-hand experiences of successful and failed endeavours gained during their years of service due to various rea- 
sons such as job mobility, resignation, retirements and death. Lejeune (2011) states that employees who leave the workplace often take valuable know-how and problem-solving skills with them, leading to an immediate loss of organisational knowledge and a host of subsequent ramifications. Sometimes, the consequences do not become obvious until long after the departure of the employee, especially in cases where the knowledge was held by a key figure, an expert, or where no one else was even aware the knowledge existed. Seidler-de Alwis and Hartmann (2004) argue that barriers to the share of tacit knowledge occur if individuals who possess knowledge essential to innovation are either discouraged from active participation or are not involved in the innovation process. Moreover, even if employees stay with the organisation, the full extent of their knowledge may not be realised and utilised unless opportunities are provided to facilitate the share of knowledge with others (Weiss, 1999, cited in Vathsala, 2015).

Sarkindaaji, Hashi, and Abdullateef (2014) assert that many public organisations, particularly in developing countries, have provided no form of incentives for employees to effectively participate in knowledge driven activities, because interactions are often rigid, limited and directed. Therefore, unless organisations facilitate the share of knowledge among employees, it is likely to lose innovative knowledge of immeasurable value accumulated over the years (see also Bojan \& Bojan, 2012; Kremp $\&$ Mairesse, 2003). There are strong arguments for the strategic use of tacit knowledge to improve innovation in the public sector, but many public organisations are not structured for the application of tacit knowledge sharing initiatives needed to improve innovation capabilities (Edge, 2005). It has been clearly established that tacit knowledge is essential for innovation in the public sector, yet the organizational context needed to support the dissemination of this knowledge is lacking in practice (Lewis, Ricard, \& Klijn, 2017; McNabb, 2007). This may undermine innovative efforts or activities because tacit knowledge would become fragmented, redundant and underutilised (Syed lkhsan, 2005). Hence, unless relevant tacit knowledge is shared, innovation cannot be created or sustained (Seidlerde Alwis et al., 2004; J. Wang \& Yang, 2015).

Zhou and Nunes (2015) state that up to 80 percent of organisational knowledge is synthesised in tacit form, which may be higher in public organisations when compared with explicit knowledge. Smith (2001) argues that tacit knowledge is often out of sight, underrated and underutilised in the workplace. Nearly two-thirds of work-related information that is gradually transformed comes from personal contacts and interactions. This intuitive, creative conversation often occurs when people exchange ideas and practicalities in an open and supportive environment. It is essential for organisations to frame solutions from diverse viewpoints in such an interactive process to produce ideas that are channelled into new or improved processes and services. Seidler-de Alwis et al. (2004) draw an assumption that the more tacit knowledge is involved in the innovation process, the more likely it will have a positive impact on innovation success. As a result of the turbulent environments, public organisations deal with complex problems they do not completely understand and that demands thinking from a new or different perspective to create innovative solutions. Tacit knowledge is deemed important in producing innovations that can accommodate these emerging realities because of its dynamic nature (Syed lkhsan, 2005). Despite this notion, the share of tacit knowledge and how it can support innovation has yet to be investigated in the public sector of developing countries, when compared to studies in the private sector (Buheji, 2013; McEvoy, Arisha \& Ragad, 2015; Syed Ikhsan, 2005), possibly because organizational outcomes can be identified and measured there. Furthermore, there are comparatively fewer empirical works that have been able to establish a causal relationship between tacit knowledge sharing and innovation (Zaima, Gürcanb, Tarımc, Zaimb, \& Alpkanb, 2015). Still, for many, tacit knowledge sharing is a domain that is relatively unexplored and not fully understood (Seidler-de Alwis \& Hartmann, 2008), which buttresses the need for more empirical investigations to understand how the share of tacit knowledge can be used for managing current and emerging challenges in which an innovative approach is required.

Omotayo (2015) argues that tacit knowledge sharing represents a potentially very important subject area in the knowledge management domain, which not only opens up new ways of theorising about 
the nature of organisations in this knowledge era but also has the potential to improve innovations. Therefore, it is important for research to address the tacit component to inform our actions on where and how much effort we should invest in the verbalisation or explication of tacit knowledge to create innovations, since it runs the risk of loss if not shared to others (see also Seidler-de Alwis \& Hartmann, 2008). Drawing from the related literature, this study creates several hypotheses to examine the relationship between knowledge sharing and innovation success, and is expected to contribute empirically to the burgeoning literature from a public sector and developing country context.

\section{LITERATURE REVIEW}

\section{KNOWLEDGE SHARING}

There are similar terms used to describe the process of knowledge sharing in literature, which includes knowledge diffusion, knowledge transfer, knowledge distribution, knowledge dissemination and information sharing (Najla, Filipovic, \& Kovac, 2017). Knowledge sharing can be seen as the process of engaging in social and collaborative interactions for the exchange of context-specific knowledge, skills, and experience within and across organisational boundaries. Knowledge sharing comprises two parts, which are knowledge donating and knowledge collecting. Knowledge donating involves communicating with others based on one's knowledge. It represents the willingness of individuals to clearly express or externalise their knowledge to others to help them develop their personal knowledge and solve problems more effectively. This dimension deals with the supply of new knowledge (De Vries, Van Den Hooff, \& De Ridder, 2006). The drive behind donating knowledge is to convert it from tacit to explicit knowledge and enable it to turn to organizational knowledge (Hussein, Singh, Farouk, \& Sohal, 2016). In contrast, knowledge collecting deals with interactions or consultations with other individuals to get them to share their knowledge. An individual is the recipient or receiver of knowledge, who must consult, ask for, accept, learn from or adopt the knowledge of other individuals. The aim of knowledge collecting is to internalise the knowledge of other individuals through observation, listening and practice (see Yesil et al., 2013). This dimension deals with the demand of new knowledge; that is, specific request for knowledge (De Vries et al., 2006). However, these two distinct knowledge sharing components are active processes in the sense that one is either engaged in active communication with others for the purpose of knowledge transfer, or consulting others to gain some level of access to their intellectual capital (De Vries et al., 2006; Van Den Hooff \& De Ridder, 2004, cited in Kamasak \& Bulutlar, 2010).

Tacit knowledge can be transmitted through socialisation processes such as apprenticeship, mentoring, coaching, interaction, observation, imitation, storytelling and narratives, or externalisation processes like assumptions, analogies and metaphors with successful tacit knowledge transfer influenced by context/situation fit and understanding (Matošková et al., 2013). For knowledge sharing to be effective, it is important that the knowledge fits the specific context in terms of relevance, interpretation, and understanding. In another work setting, the effort to share similar knowledge may not yield the required results. Krogh, Ichijo and Nonaka (2002, p. 45) assert that "for knowledge to be shared in a social context, individuals must rely on others to listen and react to their ideas. Constructive and helpful relations enable people to share their insights and freely discuss their concerns". Knowledge sharing can be disrupted when: (i) the tacit knowledge shared is considered ambiguous; (ii) the receiver lacks the absorptive capacity to deal with the ambiguity; (iii) the sender and receiver have a difficult or less defined relationship; and (iv) the emotional factors such as power, fear, likes or dislikes, trust, willingness to share, etc., are neglected (Goh Guan Gan, Ryan, \& Gurujan, 2006; Seidler-de Alwis \& Hartmann, 2008).

The core of knowledge sharing lies in explicating the accessible particulars of an individual's tacit components to address current situations or problems as well as those likely to occur in the future. It has been argued (e.g. Polanyi, 2009) that tacit knowledge cannot be codified but displayed in what we do, specifically in our actions, interaction and involvement at work. This knowledge often must be 
inferred from actions and statements, and functions as background knowledge that assist in carrying out tasks, reacting to unforeseen circumstances or innovating (Lejune, 2011). Through situated interactions at work, we develop new mental models/perspectives/ideas or tacitly identify trends and anomalies in specific work context or setting that can be explicated with considerable effort. These implicit expressions are sometimes brought to bear explicitly in an attempt to make sense of a given situation, which are in most cases tested for relevance and effectiveness (Garcia \& Coltre, 2017). Importantly, knowledge sharing has been identified as a focal area in innovative and knowledge-based organisations, and the relevance of this construct is derived from the fact that it provides a link between where knowledge resides and where knowledge can be utilised to attain maximum value (Najla et al., 2017; Yesil, 2014). The knowledge rooted in the individual actions and interactions endows organisation with competitive advantages for growth and survival (Trigo, 2014). In subsequent sections, knowledge sharing process, knowledge sharing dimensions and knowledge sharing practices were used interchangeably to reflect the bidirectional nature of knowledge sharing; that is, knowledge donating and knowledge collecting.

\section{INNOVATION SUCCESS}

The Australian National Audit Office (2009) argues that the driving imperative for innovation is the need to fashion new ways to respond effectively to changing work context and societal expectation in an uncertain environment. Innovation is essential for organisational survival and growth and will play a more salient role in the future of public organisations looking to reinvent themselves to address complex problems with limited resources. Innovation is a necessary element if public organisations are to become better targeted, efficient and more responsive to changing societal needs. However, it should be seen as a collaborative, dynamic process that involves different parts of the organisation and outside partners creating and exploiting new opportunities and finding new ways to solve complex problems (EY, 2017). To this end, public organisations will not only practice innovation, but refine innovations to improve experience and build capabilities to provide support for it. Yesil et al. (2013) opine that innovation success is the performance of an organisation going through the different types of innovation to achieve an overall improvement of its innovation capability. Evidently, innovative organisations invest and nurture innovation capabilities from which they execute effective innovation processes, leading to innovation in services, policies and processes. Innovation success lies in the fact that the innovation process creates an organisation prepared to meet the changing needs and conditions in the environment given certain knowledge resources at the disposal of public organisations. Therefore, it is vital for public organisations to improve the quality of their experiential knowledge through observation and interaction with relevant stakeholders. Košmrlj, Sirok and Lika (2015) stress that public organisations should observe stakeholders response to their actions through an iterative learning process that leads to the formation or reframing of an innovation. Since the imperative of the innovation system is centred on meeting the shifting public expectations and demands through quality improvements or integration in services, processes and policies, success is realised when the innovation process aligns effectively with these changing expectations and demands. Essentially, creative efforts should focus on making distinctive quality adjustments, modifications or expansions in the innovation system to enable public organisations stay in close contacts with the trends and events as they emerge. However, for the purpose of this paper, innovation success is improvements in the effectiveness of innovative activities and potential to generate innovative outputs.

\section{KNOWLEDGE SHARING AND INNOVATION SUCCESS}

Aulawi et al. (2009, cited in Yesil et al., 2013) argued that knowledge can be disseminated, developed, and integrated through the development of knowledge sharing. Knowledge sharing practices can stimulate individual to think more critically and more creatively, so they finally can create new knowledge. Al-Husseini and Elbeltagi (2015a) argued that sharing knowledge as a strategic resource is one of the foundational tools that enable organisations to increase their competitive leverage and 
chances of survival through innovation exponentially. They also conducted a comparative study, which reiterated the significant positive relationship between the knowledge sharing dimensions and innovation (Al-Husseini and Elbeltagi, 2015b). These knowledge sharing practices are vital in any organization as this is the basis upon which ideas are being developed and implemented. A thorough understanding of these knowledge sharing practices will enable organisations capitalise on knowledge, to influence their innovation capability positively and significantly (Abdallah et al., 2012). Lin (2007) argued that employees' willingness to collect and donate knowledge brings about significant improvements in an organisation's innovation capability. In fact, it can be said that the relationship between the knowledge sharing process and innovation capability may provide a clue on how organisations create a knowledge sharing culture to sustain their innovation performance (see also Najla et al., 2017). Yesil et al. (2013) argued that the improvement of innovation capability may cause knowledge sharing practices to impact on innovation positively. Hu, Horng and Sun (2009) argued that to achieve high innovation performance, organisations need to develop a better knowledge sharing process. Numerous studies conducted over the past decade regard knowledge sharing process as an important factor in strengthening innovation performance of organisations (e.g., Lee \& Hidayat, 2018; Leonardi, 2014; Melhem \& Norsiah, 2014; Z. Wang \& Wang, 2012; Yeşil, 2014). Hussein et al. (2016) argued that employee willingness to share knowledge partially influences firm innovation capability, with knowledge donating having no influence on firm innovation capability and knowledge collecting having a positive influence on firm innovation capability, whereas Islam, Agarwal, and Ikeda (2017) argued that the effect of knowledge sharing on innovation is insignificant unless it yields new knowledge. The Asian Productivity Organisation (2013) argued that the ultimate goal of the knowledge sharing process is to spark innovations by allowing people to interact, think more creatively and work more productively Knowledge itself is a static resource which needs to be vitalised, shared and diffused to create value. Ferretti and Afonso (2017) argued that in the interchangeable socialisation of knowledge, new ideas are formed and the foundation is created for the development of new or improved services, policies or processes with the possibility of developing innovative mechanisms and processes. Based on these arguments, this study hypothesised that:

Ha: Knowledge donating is positively related to innovation success.

$H b$ : Knowledge collecting is positively related to innovation success

\section{METHODOLOGY}

\section{SAMPLE AND DATA COLLECTION PROCEDURE}

The sample frame comprises twelve public organisations drawn from the health and education sector in South-South, Nigeria. When selecting samples for studies of this nature, it is apt to include respondents from knowledge-intensive organisations and positions. In addition, the public organisations selected have private-sector competition, which follows the competition thesis that competitive pressures from private organisations spur performance improvement vis-a-vis efficiency and value creation in public organisations as well as previously monoplistic setting (Ramaswamy \& Renforth, 1996). The data used was obtained from (i) a questionnaire designed based on related studies, and (ii) secondary sources - journals and conference proceedings were also used to interpret and provide contextual information to the primary data. For the secondary sources, this study did not limit itself to a particular industry or sectors in data search. So far, the constructs under investigation are reflected in the sources, they were considered for inclusion. Furthermore, higher consideration was granted to research papers published or carried out after 2000. But some papers with a publication date before 2000 were also considered to obtain theoretical background. Selecting 587 respondents from the target population is considered adequate and representative using the Cochran's sample size determination formula. The questionnaire was self-administered with a covering letter, and 384 completed questionnaires were returned, thereby constituting a return rate of 65.4 percent. Out of the 384 completed questionnaires, 326 representing 84.9 percent were from state universities and 58 representing 15.1 percent were from state hospitals. 


\section{MEASURES}

The original measurement items from previous studies were used to develop the questionnaire with minor modification to fit the nature of this study. The items were assessed on a five-point Likert scale, ranging from 1 (strongly disagree) to 5 (strongly agree). Knowledge sharing and innovation success items were taken and adapted to this study from De Vries et al. (2006), Melhem and Norsiah (2014), Z. Wang and Wang (2012), and Yesil et al. (2013). In the pre-test, the questionnaire was face validated by five management experts from the University of Nigeria and six respondents from the target organisations were asked to identify whether they may be interpretation errors or question design problems. Following the constructive responses, some questions were modified slightly to improve clarity, relevance, comprehensiveness and ease of understanding before inclusion in the final draft. Fifty copies of the questionnaire were self-administered through convenient sampling on the intended respondents to ascertain the reliability of the research instrument, with forty seven valid responses after removing three uncompleted questionnaires. This study calculated the Cronbach's alpha with the aid of the SPSS 20.0, and the resulting values of knowledge donating $(\alpha=0.814)$, knowledge collecting $(\alpha=0.769)$, and innovation success $(\alpha=0.799)$ were above the minimum acceptable value of 0.70 , indicating satisfactory reliability. The measurement items for the constructs see listed in Appendix A.

\section{DATA ANALYSIS}

The Partial Least Square (PLS) path modelling was adopted for data and hypotheses testing. PLS is a multivariate data analysis method designed to explain variance and predict relationships among constructs. The PLS makes no data assumption, places minimal condition on sample size and can be used for residual distribution. The PLS model was analysed using SmartPLS 3. According to Yesil et al. (2013), SmartPLS explains the psychometric properties of the measurement model and estimates the parameters of the structural model simultaneously. This study followed the two-step estimation procedure suggested by Anderson and Gerbing (1988). This procedure ensured that the constructs' measures are valid and reliable before attempting to establish the relationship among constructs. The first step is the confirmatory factor analysis (CFA) of the measurement model; that is, instrument validation. The reflective measurement model was assessed with six criteria: factor loading, t-test, composite reliability (CR), average variance extracted (AVE), discriminant validity (Fornell-Larcker and cross loading criterion) and multicollinearity test using the variance inflation factor (VIF). The second step involves the estimation of the structural model for hypothesis testing.

\section{RESULTS}

The demographic characteristics from the data collected shows that the ages of respondents vary between 30-39 (20.3 percent), 40-49 (48.4 percent), 50-59 (27.6 percent), and $60>$ (3.1 percent). 55.2 percent were male and 44.8 percent were female, indicating a slight difference in the gender distribution. 1.8 percent had a certificate, 5.5 percent had a graduate degree and 92.7 percent had a post graduate degree, indicating that most of the respondents were highly educated, hence, in the best position to provide appropriate answers to the questionnaire. The work experiences of respondents vary between 0-4 (10.9 percent), 5-9 (25.3 percent), 10-14 (19.3 percent), 15-20 (25.3 percent), and 20 and above (19.3 percent), indicating that a considerable number of respondents possess sufficient amount of experiential knowledge and were in an appropriate position to respond in tandem with knowledge sharing and innovation activities.

Following the procedure previously described in the methodology, the analysis of results should start with the evaluation of the measurement model of this study. The confirmatory factor analysis was performed to determine the relationship between the latent constructs (i.e. knowledge donating, knowledge collecting and innovation success) and their indicators. The factor loadings of the measurement indicators show that all items were within the satisfactory range of $>0.707$ as recommended by Chin (1998) and Hair, Hult, Ringle, and Sarstedt (2013). Knowledge donating indicators ranged 
from 0.848 to 0.887 , knowledge collecting indicators ranged from 0.858 to 0.908 , and innovation success indicators ranged from 0.732 to 0.846 (see Table 2). Therefore, all items correlated strongly with their underlying constructs and were retained in the measurement model. The t-values of the measurement indicators show that all the items were $>1.96$, indicating that the items had statistical significance to the underlying constructs. Knowledge donating indicators ranged from 53.847 to 68.515, knowledge collecting indicators ranged from 57.548 - 92.595, and innovation success indicators ranged from 20.442 to 62.420 . The results of the measurement model as shown in Table 1 show that the $\mathrm{CR}$ values were above the acceptable threshold of $>0.7$, indicating strong reliability. The AVE values exceeded the acceptable level of 0.50 as recommended by Henseler, Ringle and Sinkovics (2009), demonstrating a satisfactory convergent validity. Also, this indicates that 50 percent or more of the constructs' variability is as a result of its own indicators. Discriminant validity is established when the AVE values are greater than the inter-construct correlations. The result shows evidence of discriminant validity of constructs. The multicollinearity test shows that the VIF values were all less than the cut off value of 5.0 recommended by Hair et al. (2013), confirming that there is no multicollinearity problem among the constructs. In addition, the inferences made from the measurement model were deemed reliable because both independent constructs are not perfectly correlated.

Table 1. Reliability, validity and multicollinearity test

\begin{tabular}{lllllll}
\hline \multirow{2}{*}{ Indicators } & \multicolumn{9}{c}{ Discriminant Validity } & & & \\
\cline { 2 - 4 } & 1 & 2 & 3 & CR & AVE & VIF \\
\hline Knowledge Donating & $\mathbf{0 . 8 6 7}$ & & & 0.924 & 0.751 & 1.087 \\
Knowledge Collecting & 0.282 & $\mathbf{0 . 8 8 8}$ & & 0.937 & 0.788 & 1.087 \\
Innovation Success & 0.495 & 0.346 & $\mathbf{0 . 7 9 4}$ & 0.911 & 0.631 & \\
\hline
\end{tabular}

Table 2. Factor loading and cross loadings

\begin{tabular}{llll}
\hline Indicators & KD & KC & IS \\
\hline KD1 & $\mathbf{0 . 8 6 1}$ & 0.260 & 0.390 \\
KD2 & $\mathbf{0 . 8 4 8}$ & 0.265 & 0.459 \\
KD3 & $\mathbf{0 . 8 7 0}$ & 0.197 & 0.446 \\
KD4 & $\mathbf{0 . 8 8 7}$ & 0.258 & 0.413 \\
KC1 & 0.216 & $\mathbf{0 . 9 0 1}$ & 0.245 \\
KC2 & 0.247 & $\mathbf{0 . 8 8 4}$ & 0.305 \\
KC3 & 0.255 & $\mathbf{0 . 8 5 8}$ & 0.329 \\
KC4 & 0.275 & $\mathbf{0 . 9 0 8}$ & 0.332 \\
IS1 & 0.493 & 0.315 & $\mathbf{0 . 8 4 6}$ \\
IS2 & 0.438 & 0.281 & $\mathbf{0 . 8 3 4}$ \\
IS3 & 0.452 & 0.335 & $\mathbf{0 . 8 1 5}$ \\
IS4 & 0.309 & 0.217 & $\mathbf{0 . 7 7 6}$ \\
IS5 & 0.324 & 0.268 & $\mathbf{0 . 7 5 8}$ \\
IS6 & 0.244 & 0.178 & $\mathbf{0 . 7 3 2}$ \\
\hline
\end{tabular}

Note: $\mathrm{KD}=$ Knowledge donating, $\mathrm{KC}=$ Knowledge collecting, IS= Innovation success

The convergent validity was also tested by extracting the factor loadings and cross-loading of the indicators of the latent constructs. The results shown in Table 2 demonstrate that the indicators loaded on their respective constructs than any other constructs. Importantly, convergent validity 
is achieved when the indicators load greater than 0.70 on their respective construct than the other constructs (Yoo \& Alavi, 2001, cited in Yesil et al., 2013). This result supports the convergent validity among the constructs.

Overall, the measurement model has satisfactory values for all the quality criteria. Collectively, these results provide evidence that validates the appropriateness of the measurement model for this study. However, after the quality of the measurement model was ascertained in step one; the structural model was created to assess the significance of the hypothesised paths. The model was evaluated based on beta values, t-values, $\mathrm{R}$-square $\left(\mathrm{R}^{2}\right)$ and $\mathrm{p}$-values. The results of the analysis are depicted in Figure 1 and summarised in Table 3.

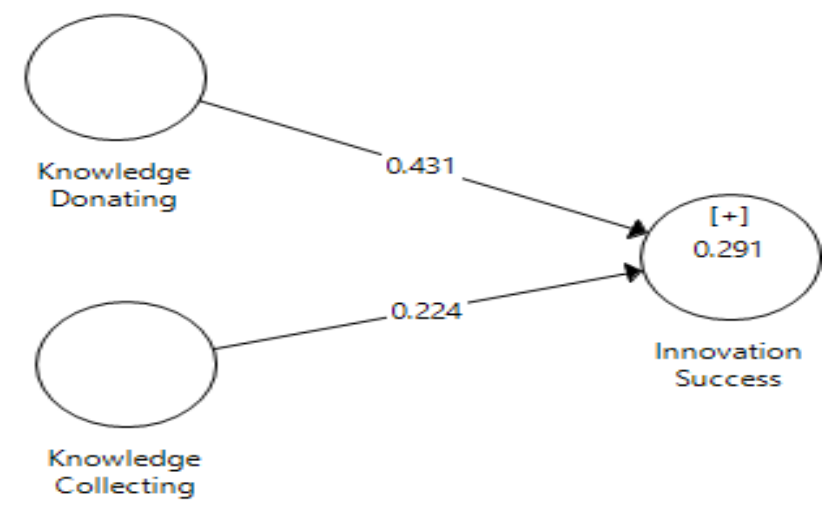

Figure 1. The structural model with path coefficients and R-square

Figure 1 shows the beta coefficients of the different paths and $\mathrm{R}^{2}$. The $\mathrm{R}^{2}$ indicated that knowledge sharing process i.e. knowledge donating and knowledge collecting can account for 29.1 percent of the variation in innovation success. The remaining 70.1 percent can be linked to other factors not included in this study. Falk and Miller (1992, cited in Ferreras-Mendez, Newell, Fernandez-Mesa, \& Alegre, 2015) state that the value must be greater than 0.1 , which ensures at least 10 percent of variability is explained from the model. Lower $\mathrm{R}^{2}$ values, in spite of being significant, provide little information, so the hypothesis regarding latent construct cannot be sustained.

Table 3. Structural model estimates

\begin{tabular}{llllll}
\hline Hypotheses & Path (Relationship) & Beta & T-value & P-value & Support \\
\hline $\mathrm{Ha}$ & $\begin{array}{l}\text { Knowledge Donating } \\
\rightarrow \text { Innovation Success }\end{array}$ & 0.431 & 7.506 & 0.000 & Yes \\
$\mathrm{Hb}$ & $\begin{array}{l}\text { Knowledge Collecting } \\
\rightarrow \text { Innovation Success }\end{array}$ & 0.224 & 4.630 & 0.000 & Yes \\
\hline
\end{tabular}

Note: $\mathrm{p}<0.05$

Table 3 shows the estimates of the structural model, where the beta values of the path coefficient indicate the direct effects of the independent latent constructs on the dependent latent construct; $t$ values indicate the statistical importance of the hypothesised paths to the structural model; and the $p$-values indicate the significance of the results. From the estimates, knowledge donating $(\beta=0.431$, $7.506>1.96, \mathrm{p}<0.05)$ and knowledge collecting $(\beta=0.224,4.630>1.96, \mathrm{p}<0.05)$ were found to have a significant positive relationship with innovation success. Statistically, knowledge donating had a much stronger relationship with innovation success than that of knowledge collecting and innovation success. However, the results support hypotheses $\mathrm{Ha}$ and $\mathrm{Hb}$. 


\section{CONCLUSION}

This study integrated two important organisational constructs: knowledge sharing and innovation success. Specifically, it investigated the effects of knowledge donating on innovation success and knowledge collecting on innovation success. The knowledge type examined was tacit knowledge. The results obtained are interesting for both theory and practice. In theory, this study adds to the burgeoning literature that linked empirically the tacit knowledge sharing process with innovation success. Thus, it extends the applicability of research and generalisation of results from previous investigations (e.g., Al-Husseini \& Elbeltagi, 2015a; Z. Wang \& Wang, 2012; Yesil et al., 2013) in the developing country context; that is, Nigeria. The structural model demonstrated quite a significant support for the hypothesised relationship, which showed that knowledge sharing through knowledge donating and collecting enhances innovation success of public organisations. The results support the theoretical arguments in previous studies (e.g., Al-Husseini \& Elbeltagi, 2015a, 2015b; Lee \& Hidayat, 2018; Leonardi, 2014; Lin, 2007; Melhem \& Norsiah, 2014; Najla et al., 2017; Z. Wang \& Wang, 2012; Yeşil, 2014; Yesil et al., 2013) that knowledge sharing through donating and collecting contributes to innovation success. The results somewhat agree with Hussein et al. (2016) that employee willingness to share knowledge partially influences firm innovation capability, with knowledge donating having no influence on firm innovation capability and knowledge collecting having a positive influence on firm innovation capability. It can be said that knowledge collecting is analogous to learning because it is through collecting of knowledge that individuals are able to reflect, understand, synthesise and externalise valuable knowledge, thus, extending or reframing knowledge utilised for innovative activities. Furthermore, knowledge collecting affects not just the knowledge at the cognitive level but also the behaviour of individuals in the application of knowledge in specific work contexts (Wipawayangkool \& Teng, 2016). The results contradict the findings of Islam et al. (2017) that the effect of knowledge sharing on innovation is insignificant. The possible reason for this is that knowledge sharing effect is inconsequential on innovation unless it results in the addition of value or enables new actions through learning or the creation of new knowledge. Knowledge sharing is the basis upon which new ideas are created in an attempt to enhance innovation efforts. Abdallah et al. (2012) argued that the transfer of knowledge from one employee to another creates new knowledge, and subsequently leads to innovation when the new knowledge is successfully applied. In tacit knowledge sharing, new ideas are formed and the foundation is created for the development of something new or improved with the possibility of developing innovative processes (Ferretti \& Afonso, 2017). However, the knowledge sharing process has an important role to play in both facilitating the creation of different ideas and in convergence of the different ideas to an actionable step or course of action in the innovation process.

The results show that the degree of significance of the knowledge sharing dimensions on innovation varies. The complementarity of knowledge donating and knowledge collecting does not imply equality in nature and symmetry because both dimensions have different nature and can be influenced by different factors (Guistiniano, Lombardi, \& Cavaliere, 2016). Hence, knowledge donating effect on innovation success was more significantly positive than the effect of knowledge collecting on innovation success. According to Garcia and Coltre (2017), the core of knowledge sharing lies in explicating the accessible particulars of an individual's tacit components to address current situations or problems as well as those likely to occur in the future. Through situated interactions at work, individuals develop new mental models or tacitly identify trends and anomalies in specific work context or setting that can be explicated with considerable effort. These implicit expressions are sometimes brought to bear explicitly in an attempt to make sense of a given situation or respond to the complexities of work situations.

In practice, the relationships among the constructs provide managerial implications for the need to strengthen knowledge sharing practices to increase tacit knowledge utilisation and workplace creativity for sustained innovation. As problem and opportunity context continue to evolve in today's work environment, emphasis should be on setting up mechanisms such as communities of practice, brain- 
storming sessions, mentoring programs, public forums and other interactive forums to better interactions and synergy among employees. Through socialisation, individuals may come to understand each other's definition of knowledge, agree on a common and justified knowledge about actions in any given work situation, and address problems and opportunities more creatively (Krogh et al., 2000). Although the knowledge sharing mechanisms used may vary based on the unique needs and demands of individuals, it enables organisations to operationalise their value chain by leveraging on what individuals know to achieve positive innovation results (McNabb, 2007). In addition, this study proposes the following practical solutions based on the findings. First, public organisations should promote a supportive culture to spur creativity through the frequent share of experiences, information and skills among the various knowledge actors. This culture type invariably incorporates and utilises different knowledge contributions in the innovation process to respond to the requirements of a changing business environment, and strengthens internal and external communication linkages to secure the desired inflow of new knowledge to drive the innovation process effectively. Second, public managers should convey the importance of knowledge sharing and its value to knowledge users in clear terms and attend to creating conditions or contexts that encourage people to share knowledge freely and willingly with others. Third, it is apt to improve organisational commitment and support for knowledge sharing activities such as mentorship programs, workshops, conferences, seminar and other related training and development programs in order to provide opportunities for employees to develop innovation competencies from the transfer of tacit knowledge developed over time from experience. Finally, to optimise innovation outcomes from knowledge sharing activities, knowledge sharing should be in tandem with the industry or global best practices. Adherence to best practices in the knowledge sharing domain may bring about improvements in the knowledge sharing dimensions; that is, donating and collecting, and subsequently impact on innovation positively.

However, like every study, the findings summarised in this study should be taken with consideration of some limitations. This study was highly subjective; employees may overstate or hide certain information with strong implications to the research findings. To an extent, this could limit the generalisability and applicability of findings. It is important to add interviews to provide depth in terms of insights and substance to the questionnaire. This study focus was on state-owned public organisations. Future studies may extend to public organisation with different ownership structure to broaden our understanding and fill in knowledge gaps.

\section{REFERENCES}

Abdallah, S., Khalil, A., \& Divine, A. (2012). The impact of knowledge sharing on innovation capability in United Arab Emirates Organisations. International Journal of Social, Behavioural, Educational, Economic, Business and Industrial Engineering, 6(12), 3588-3591. https://doi.org/10.5281/zenodo.1058771

Al-Baporikar, N. (2014). Knowledge management initiatives in Indian public sector. In Y. Al-Bastaki \& A. Shajera (Eds.), Building a competitive public sector with knowledge management strategy (pp. 53-89), Hershey: Business Science Reference. https://doi.org/10.4018/978-1-4666-4434-2.ch002

Al-Husseini, S., \& Elbeltagi, I. (2015a). Knowledge sharing practices as a basis of product innovation: A case of higher education in Iraq. International Journal of Social Science and Humanity, 5(2), 182-185. https://doi.org/10.7763/IJSSH.2015.V5.449

Al-Husseini, S., \& Elbeltagi, I. (2015b). The role of knowledge sharing in enhancing innovation: A comparative study of public and private higher education institutions (HEIs) in Iraq. Innovations in Education and Teaching International, 55(1), 23-33. https://doi.org/10.1080/14703297.2015.1122544

Anderson, C. J. \& Gerbing, W. D. (1988). Structural equation modelling in practice: A review and recommended two-step approach. Psychological Bulletin, 103(3), 411-423. https://doi.org/10.1037/0033-2909.103.3.411

Asian Productivity Organisation (2013). Knowledge management for the public sector. Tokyo: Asian Productivity Organisation.

Australian National Audit Office (2009). Innovation in the public sector: Enabling better performance, driving new directions. Canberra, Australia: Australian National Audit Office. 
Knowledge Sharing Process and Innovation Success

Bojan, B., \& Bojan, P. (2012). The role of knowledge management in increasing enterprise's innovativeness. Economics and Organisation, 9(1), 92-110.

Buheji, M. (2013). Knowledge management influence on government organisations competitiveness (Doctoral dissertation, Brunel University, London). Retrieved from http://bura.brunel.ac.uk/handle/2438/7236

Chin, W. W. (1998). The partial least squares approach to structural equation modelling. In G. A. Marcoulides (Ed.). Modern methods for business research (pp. 295-336). New Jersey: Erlbaum.

De Vries, E. R., Van Den Hooff, B., \& De Ridder, A. J. (2006). Explaining knowledge sharing: The role of team communication styles, job satisfaction and performance beliefs. Communication Research, 33(2), 115-135. https://doi.org/10.1177/0093650205285366

Edge, K. (2005). Powerful public sector knowledge management: a school district example. Journal of Knowledge Management, 9(6), 45-52. https://doi.org/10.1108/13673270510629954

EY (2017). Public sector innovation: From ideas to actions. Retrieved from www.ey.com/ca

Ferreras-Mendez, J., Newell, S., Fernandez-Mesa, A., \& Alegre, J. (2015). Depth and breadth of external knowledge search and performance: The mediating role of absorptive capacity. Industrial Marketing Management, 47, 86-97. https://doi.org/10.1016/j.indmarman.2015.02.038

Ferretti, R. J., \& Afonso, C. M. (2017). Tacit knowledge sharing: A literature review applied to the context of the Brazilian Judiciary. https://doi.org/10.5772/intechopen.70066

Garcia G. P. O., \& Coltre, M. S. (2017). Knowledge management as a determining factor in the retention of professionals in the industry: A case study in an organisation in the furniture industry. Brazilian Business Review, 14(2), 182-203. https://doi.org/10.15728/bbr.2017.14.2.3

Goh Guan Gan, G., Ryan, C., \& Guruajan, R. (2006). The effects of culture on knowledge management practice: A qualitative case study of multimedia super corridor status companies, Kajian Malaysia, 24(2), 97-128.

Guistiniano, L., Lombardi, S., \& Cavaliere, V. (2016). How knowledge collecting fosters organisational creativity. Management Decision, 54(6), 1464-1496. https://doi.org/10.1108/MD-04-2015-0111

Hair, J. F., Hult, G. T. M., Ringle, C., \& Sarstedt, M. (2013). A primer on partial least squares structural equation modelling (PLS-SEM). Thousand Oaks, CA: Sage Publications

Henseler, J., Ringle, C. M., \& Sinkovics, R. R. (2009). The use of partial least squares path modelling in international marketing. Advances in International Marketing, 20, 277-319. https://doi.org/10.1108/S14747979(2009)0000020014

Hu, M. M., Horng, J., \& Sun, C. Y. (2009). Hospitality teams: Knowledge sharing and service innovation performance. Tourism Management, 30(1), 41-50. https://doi.org/10.1016/j.tourman.2008.04.009

Hussein, T. T. A., Singh, K. S., Farouk, S., \& Sohal, S. A. (2016). Knowledge sharing enablers, processes and firm innovation capability. Journal of Workplace Learning, 28(8), 484-495. https://doi.org/10.1108/JWL-05$\underline{2016-0041}$

Islam, A. M., Agarwal, K. N., \& Ikeda, M. (2017). Effect of knowledge management on service innovation in academic libraries. International Federation of Library Associations and Institutions, 43(4), 266-281. https://doi.org/10.1177/0340035217710538

Kamasak, R., \& Bulutlar, F. (2010). The influence of knowledge sharing on innovation. European Business Review, 22(3), 306-317. https://doi.org/10.1108/09555341011040994

Košmrlj, K., Širok, B., \& Lika, B. (2015). The art of managing innovation problems and opportunities, Koper: University of Primorska.

Kremp, E., \& Mairesse, J. (2003). Knowledge management, innovation and productivity: A firm level exploration based on the French CIS3 data. In OECD/Minister of Industry Canada (Ed.), Measuring knowledge management in the business sector (pp. 143-168). Cambridge. https://doi.org/10.3386/w10237

Krogh, G., Ichijo, K. \& Nonaka, I. (2002). Enabling knowledge creation: How to unlock the mystery of tacit knowledge and release the power of innovation, New York: Oxford University Press. 
Lee, C., \& Hidayat, N. (2018). The influence of knowledge sharing on service innovation performance: An empirical study on hotels in North Borneo, Indonesia. Eurasian Journal of Business and Management, 6(2), 2332. https://doi.org/10.15604/ejbm.2018.06.02.003

Lejeune, M. (2011). Tacit knowledge: Revisiting the epistemology of knowledge. Journal of Education, 46(1), 91106. https://doi.org/10.7202/1005671ar

Leonardi, M. P. (2014) Social media, knowledge sharing, and innovation: Toward a theory of communication visibility. Information Systems Research, 25(4), 796-816. Retrieved from http://dx.doi.org/10.1287/isre.2014.0536 https://doi.org/10.1287/isre.2014.0536

Lewis, M. J., Ricard, M. L., \& Klijn, H. E. (2017). How innovation drivers, networking and leadership shape public sector innovation capacity. International Review of Administrative Sciences, 82(2), 288-307. https://doi.org/10.1177/0020852317694085

Lin, H. (2007). Knowledge sharing and firm innovation capability: An empirical study. International Journal of Manpower, 26(3/4), 315-332. https://doi.org/10.1108/01437720710755272

Matošková, J., Řeháčková, H., Sobotková, E., Polčáková, M., Jurásek, M., Gregar, A., \& Švec, V. (2013). Facilitating leader tacit knowledge acquisition. Journal of Competitiveness, 5(1), 3-15. https://doi.org/10.7441/joc.2013.01.01

McEvoy, P. J., Arisha, A., \& Ragab, M. (2015). A review of knowledge management in the public sector: A taxonomy. International Forum on Knowledge Asset Dynamics, Bari, Italy. Retrieved from www.arrow.dit.ie

McNabb, E. D. (2007). Knowledge management in the public sector: A blueprint for innovation in government. New York: M.E. Sharpe.

Melhem, B. J. S., \& Norsiah, M. (2014). The influence of knowledge sharing on innovation: A study of Jordanian four and five stars hotels. In F. Lumban Gaol, W. Mars, \& H. Saragih (Eds.). Management and technology in knowledge, service, tourism and hospitality (pp. 83-88). London: Taylor \& Francis Group. https://doi.org/10.1201/b16700-19

Najla, P., Filipovic, D., \& Kovac, M. (2017). Knowledge sharing and firm innovation capability in Croatian ICT companies. International Journal of Manpower, 38(4) 632-644. https://doi.org/10.1108/IJM-04-2016-0077

Omotayo, F. O. (2015). Knowledge management as an important tool in organisational management: A review of literature. Library Philosophy and Practice (e-journal). Paper 1238.

Ondari-Okenwa, E., \& Smith, G. J. (2009). The role of knowledge management in enhancing government service-delivery in Kenya, South African Journal of Libraries and Information Science, 75(1), 28-39. https://doi.org/10.7553/75-1-1271

Polanyi, M. (2009). The tacit dimension. Chicago: University of Chicago Press.

Ramaswamy, K., \& Renforth, W. (1996). Competitive intensity and technical efficiency in public sector firms: Evidence from India. International Journal of Public Sector Management, 9(3), 4-17. https://doi.org/10.1108/09513559610124441

Sáenz, J., Aramburu, N., \& Blanco, E. C. (2012). Knowledge sharing and innovation in Spanish and Colombian high-tech firms. Journal of Knowledge Management, 16(6), 919-933. https://doi.org/10.1108/13673271211276191

Santos, D. F., \& Lopes, T. I. (2014). The linkage between tacit knowledge and models of innovation. In B. Galbraith (Ed.), Innovation and entrepreneurship (pp. 556-564). Sonning Common, UK: Academic Conferences and Publishing International Limited.

Sarkindaaji, D. B., Hashi, B. A. N., \& Abdullateef, O. A. (2014). Knowledge management and organizational performance of mobile service firms in Nigeria: A proposed framework. Information and Knowledge Management, 4(11), 88-95.

Seidler-de Alwis, R., \& Hartmann, E. (2008). The use of tacit knowledge within innovative companies: Knowledge management in innovative enterprises. Journal of Knowledge Management, 12(1), 133-147. https://doi.org/10.1108/13673270810852449 
Knowledge Sharing Process and Innovation Success

Seidler-de Alwis, R., Hartmann, E., \& Gemunden, G. H. (2004, September). The role of tacit knowledge in innovation management. Paper presented at the 20th Annual IMP Conference, Copenhagen. Retrieved from www.impgroup.org/uploads/papers/4585.pdf

Smith, A. E. (2001). The role of tacit and explicit knowledge in the workplace. Journal of Knowledge Management, 5(4), 311-321. https://doi.org/10.1108/13673270110411733

Syed lkhsan, S. O. S. (2005). Knowledge management in a public organisation: A study of the performance of knowledge transfer in the Ministry of Entrepreneur Development of Malaysia (Doctoral dissertation, Loughborough University, Loughborough, UK).

Trigo, A. (2014). Mechanisms of learning and innovation performance: The relevance of knowledge sharing and creativity for non-technological innovation. International Journal of Innovation and Technology Management, 10(6), 1-27. https://doi.org/10.1142/S0219877013400282

Vathsala, W. (2015). Knowledge sharing and service innovativeness in offshore outsourced software development firms. VINE, 45(1), 2-21. https://doi.org/10.1108/VINE-03-2013-0010

Wang, Z., \& Wang, N. (2012). Knowledge sharing, innovation and firm performance. Expert Systems with Applications, 39, 8899-8908. https://doi.org/10.1016/j.eswa.2012.02.017

Wang, J. \& Yang, J. (2015). An empirical study of employees' tacit knowledge sharing behavior. Journal of Systems Science and Information, 3(3), 264-278. https://doi.org/10.1515/JSSI-2015-0264

Wipawayangkool, K., \& Teng, J. (2016). Assessing tacit knowledge and sharing intention: A knowledge internalization perspective. Knowledge and Process Management, 23(3), 194-206. https://doi.org/10.1002/kpm.1505

Xiang, C., Yong, S., \& Guo, C. (2009). A study on co-interaction between knowledge sharing and service innovation based on team climate. International Conference on Information Management, Innovation Management and Industrial Engineering. https://doi.org/10.1109/ICIII.2009.512

Yeşil, S. (2014). Exploring the links among organisational commitment, knowledge sharing and innovation capability in a public organisation. European Journal of International Management, 8(5), 506-527. https://doi.org/10.1504/EJIM.2014.064602

Yesil, S., Koska, A., \& Buyukbese, T. (2013). Knowledge sharing process, innovation capability and innovation performance: An empirical study. Procedia Social and Behavioural Sciences, 75, 217-225. https://doi.org/10.1016/j.sbspro.2013.04.025

Zaima, H., Gürcanb, F. O., Tarımc, M., Zaimb, S., \& Alpkan, L. (2015). Determining the critical factors of tacit knowledge in service industry in Turkey. Procedia Social and Behavioral Sciences, 207, 759-767. https://doi.org/10.1016/i.sbspro.2015.10.156

Zhou, L. \& Nunes, B. M. J. (2015). Knowledge sharing in Chinese hospitals: Identifying sharing barriers in traditional Chinese and Western medicine collaboration. New York: Springer. 


\section{APPENDIX}

\section{Knowledge Sharing and Innovation Success Measurement Scale}

Knowledge Donating Measurement Scale

KS1: When I learn something new, I tell colleagues within my department about it

KS2: I share any experience, skill or insights I have with colleagues within my department when they ask for it

KS3: When I learn something new, I tell colleagues outside my department about it

KS4: I share any experience, skills or insights I have with colleagues outside my department when they ask for it

\section{Knowledge Collecting Measurement Scale}

KC1: When colleagues within my department learn something new, they tell me about it

KC2: Colleagues within my department share their experiences, skills or insights with me when I ask them to

KC3: When colleagues outside my department learn something new, they tell me about it

KC4:Colleagues outside my department share their experiences, skills or insights with me when I ask them to

\section{Innovation Success Measurement Scale}

IS1: In my organisation, ideas are developed within expected timeframe

IS2: My organisation is quick to introduce services, processes or policies that embody new ideas to the public

IS3: My organisation adapts its services, processes or policies from recent experiences

IS4: Employees are able to interact and contribute effectively in developing new services, processes or policies

IS5: In developing new services, processes or policies, employees and consumers collaborate closely

IS6: My organisation provides training for members of staff 


\section{BIOGRAPHIES}
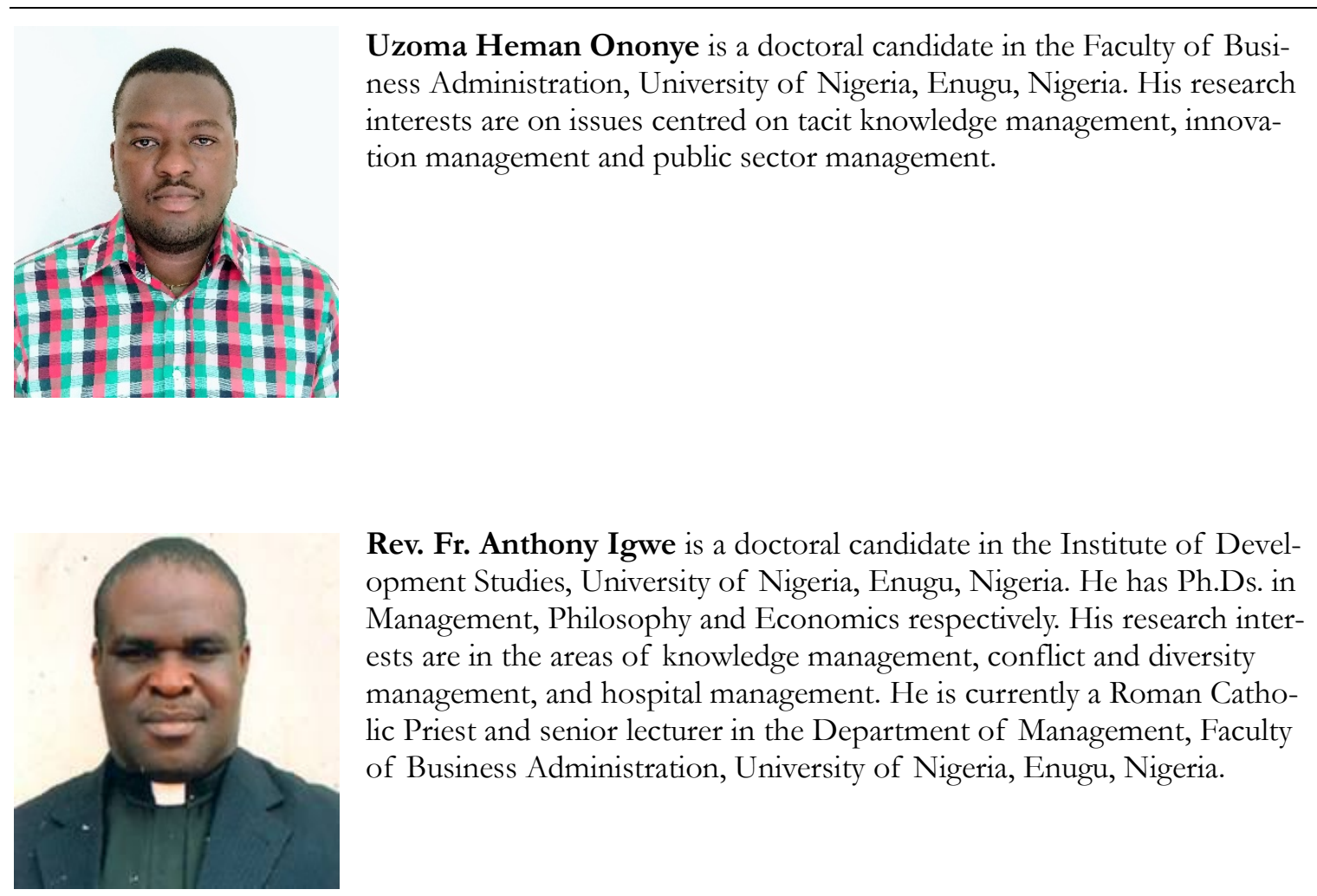

Rev. Fr. Anthony Igwe is a doctoral candidate in the Institute of Development Studies, University of Nigeria, Enugu, Nigeria. He has Ph.Ds. in Management, Philosophy and Economics respectively. His research interests are in the areas of knowledge management, conflict and diversity management, and hospital management. He is currently a Roman Catholic Priest and senior lecturer in the Department of Management, Faculty of Business Administration, University of Nigeria, Enugu, Nigeria. 